\title{
Metal ion-binding properties of the L-aspartic acid and tartaric acid, a comparative investigation. How can be increased the dosage of mineral absorption in the body
}

\author{
Seyed Ali Akbar Sajadi
}

Sharif University of Technology, Institute of Water \& Energy, Tehran, Iran.

Email:sajadi@sharif.ac.ir

Received 9 May 2010; revised 5 June 2010; accepted 9 June 2010.

\begin{abstract}
A comparative research has been developed for acidity and stability constants of M(TTA) ${ }^{1}$ and M(Asp) ${ }^{2}$ complexes which have been determined by potentiometric pH titration. Depending on metal ion-binding properties, vital differences in building complex were observed. The present study shows that in M(TTA) complexes, metal ions are coordinated to the carboxyl groups, but in M(Asp) some metal ions are able to build macrochelate over amine group. Hence, the following intermolecular and as a result independent concentration equilibrium between an open-isomer $\mathrm{M}(\mathrm{Asp})_{\mathrm{op}}$ and a closed-isomer $\mathrm{M}(\mathrm{Asp})_{\mathrm{cl}}$, has to be considered cl $\rightleftharpoons$ op. The amounts are reported. The results mentioned above demonstrate that for some M(Asp) complexes the stability constants is also largely determined by the affinity of metal ions for amine group. This leads to a kind of selectivity of metal ions and transfer them via building complexes with the aspartate. The result of this effect is a higher dosage-absorption of minerals in body. Based on the sort of metal ions, the drug-therapy can be different. For heavy metal ions this building complex helps the absorption and filtration of the blood plasma, and consequently the excursion of heavy metal ions takes place. This is an important method in microdialysis. Other metal ions such as the complexes can be considered as mineral carriers. These complexes in certain conditions ( $\mathrm{PH}-$ range) can release the minerals in body.
\end{abstract}

Keywords: Tartaric Acid; Divalent Metal Ions; Potentiometric Titration; Acidity and Stability Constants; Mineral Absorption; Minerals in Body

\footnotetext{
L-tartaric acid

${ }^{2} \mathrm{~L}$-aspartic acid
}

\section{INTRODUCTION}

It is known that metal ions are important for numerous biochemical reactions. For example, enzymes work only in the presence of such metal ions. The metal ion complexes of many amino acids have been investigated [1-6]. Surface modification of silica- and cellulose-based microfiltration membranes with functional polyamino acids for heavy metal sorption has been studied [7]. Functionalized membranes represent a field with multiple applications. Examination of specific metal-macromolecule interactions on these surfaces presents an excellent method for characterization of these materials. Ion exchange, chelation, and electrostatic interactions form the basis of metal sorption. The behavior of various materials functionalized with polypeptides and other molecules is a topic of interest because of its applications in affinity separations, biosensors, and other uses including site-specific interactions [8]. An example of the latter involves the removal of heavy metals from aqueous solutions [9-12]. These sorbents are made of a variety of materials containing many different functional groups. The advantage of affinity separations is that they may be tailored for the desired selectivity and capacity. The functionalization of materials is of vital importance for the production of new materials with specific properties. The characterization of these new materials is also critical. Enhancing micro dialysis recovery of metal ions by incorporating poly-L-aspartic acid and poly-L-histidine in the perfusion liquid has been studied [13].

A study of the evaluation of poly-L-aspartic acid and poly-L-histidine as binding agents to enhance micro dialysis recovery of metal ions is presented. Investigations were carried out to compare micro dialysis recovery for $\mathrm{Cr}, \mathrm{Cu}, \mathrm{Ni}$, and $\mathrm{Pb}$ using water as the perfusion liquid as well as applying various concentrations of poly-L-aspartic acid and poly-L-histidine in the perfusion liquid. This is aimed at understanding the mechanism of the selectivity 
of such reactions.

\section{EXPERIMENTAL}

\subsection{Materials}

The L-Aspartic acid (extra pure) was purchased from Merck, Darmstadt, Germany (Figure 1). The nitrate salt of $\mathrm{Na}^{+}, \mathrm{Ca}^{2+}, \mathrm{Mg}^{2+}, \mathrm{Mn}^{2+}, \mathrm{Co}^{2+}, \mathrm{Cu}^{2+}$, and $\mathrm{Zn}^{2+}$ (all pro analysis) were from Merck. All the starting materials were of reagent grade and used without further purification. Potassium hydrogen phthalate and standard solutions of sodium hydroxide (titrasol), nitric acid, EDTA and of the buffer solutions of $\mathrm{pH} 4.0,7.0$ and 9.0 were all from Merck. All solutions were prepared with de-ionized water. Water was purified by Milil-Q water purification system, de-ionized and distillated.

$\mathrm{pH}$ titrations

Reagents

Carbonate-free sodium hydroxide $0.03 \mathrm{M}$ was prepared and standardized against sodium hydrogen phthalate and a standard solution of nitric acid $0.5 \mathrm{mM}$. M(II) nitrate solution $(0.03 \mathrm{M})$ was prepared by dissolving the above substance in water and was standardized with standard solution of EDTA $0.1 \mathrm{M}$ (triplex).

\subsection{Apparatus}

All pH titrations were performed using a Metrohm 794 basic automatic titrator (Titrino), coupled with a thermostating bath Hero at $25^{\circ} \mathrm{C}\left( \pm 0.1^{\circ} \mathrm{C}\right)$ and a Metrohm combined glass electrode $(\mathrm{Ag} / \mathrm{AgCl})$. The $\mathrm{pH}$ meter was calibrated with Merck standard buffer solutions (4.0, 7.0 and 9.0).

\subsection{Procedure}

For the determination of acid dissociation constants of the ligand $\mathrm{L}$, an aqueous solution $(0.03 \mathrm{mM})$ of the protonated ligand was titrated with $0.03 \mathrm{M} \mathrm{NaOH}$ at $25^{\circ} \mathrm{C}$ under nitrogen atmosphere and ionic strength of $0.1 \mathrm{M}$, $\mathrm{NaNO}_{3}$. For the determination of binary (a ligand and $\mathrm{Cu}^{2+}$ ) system, the ratios used were 1:1, $\mathrm{Cu}(\mathrm{II})$ :Ligand and $1: 1, \mathrm{Cu}(\mathrm{II}): \mathrm{L}, 0.3 \mathrm{mM}$. This solution was titrated with $0.03 \mathrm{M} \mathrm{NaOH}$ under the same conditions mentioned

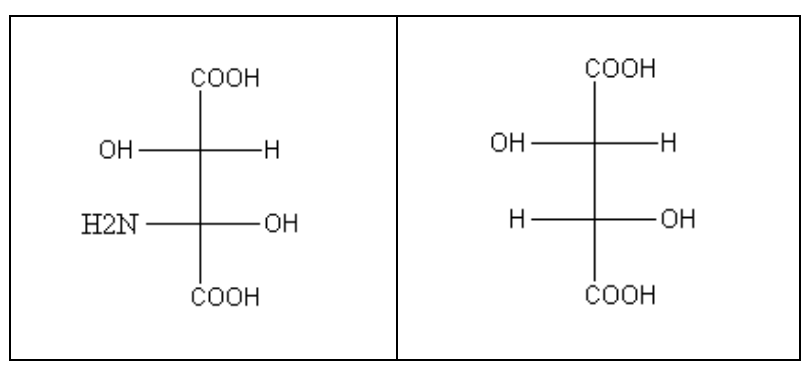

Figure 1. Chemical formula of L-aspartic acid (left) acid and L-tartaric acid (right). above. Each titration was repeated seven times in order to check the reproducibility of the data.

\subsection{Calculation}

The acid dissociation constants, $K_{H_{2}(A s p)}^{H}$ and $K_{H(A s p)}^{H}$ for $\mathrm{H}_{2}(\mathrm{~L})$ were calculated by an algebraic method. The equilibria involved in the formation of $1: 1$ complex of $\mathrm{L}$ and a divalent metal ion may be expressed as Eqs.4 \& 5 .

\subsection{Results and Discussion}

The potentiometric $\mathrm{pH}$-titrations $\left(25^{\circ} \mathrm{C}, 0.1 \mathrm{M}, \mathrm{NaNO}_{3}\right)$ were carried out to obtain the acidity and stability constants which are summarized in Table 1.

\subsection{Acidity Constants}

Lartate ion $\left(\mathrm{L}^{2-}\right),{ }^{-} \mathrm{O}_{2} \mathrm{CCH}_{2} \mathrm{CH}\left(\mathrm{NH}_{2}\right) \mathrm{CO}_{2}{ }^{-}$, is a two-basic species, and thus it can accept two protons, given $\mathrm{H}_{2}(\mathrm{~L})$, for which the following de-protonation equilibria are hold:

$$
\begin{gathered}
\mathrm{H}_{2}(\mathrm{~L}) \rightleftharpoons \mathrm{H}^{+}+\mathrm{H}(\mathrm{L})^{-} \\
K_{H_{2}(\text { Asp })}^{H}=\left[\mathrm{H}(\mathrm{L})^{-}\right]\left[\mathrm{H}^{+}\right] /\left[\mathrm{H}_{2}(\mathrm{~L})\right] \\
\mathrm{H}(\mathrm{L})^{-} \rightleftharpoons \mathrm{H}^{+}+\mathrm{L}^{2-} \\
K_{H(\text { Asp })}^{H}=\left[\mathrm{L}^{2-}\right]\left[\mathrm{H}^{+}\right] /\left[\mathrm{H}(\mathrm{L})^{-}\right]
\end{gathered}
$$

The two proton in $\mathrm{H}_{2}(\mathrm{~L})$ are certainly bound at the terminal acetate and amino groups (Figure 1), i.e., it is released from $\mathrm{HO}_{2} \mathrm{CCH}_{2} \mathrm{CH}\left(\mathrm{NH}_{3}^{+}\right) \mathrm{CO}_{2}^{-}$according to equilibrium (1) (2) (3) (4). It is known as zwitter-ion. It is also closed to the de-protonation of acetate groups which occurs at the terminal acetate groups of tartaric acid $[6,14] . \mathrm{L}^{2-}$ can release one more proton from the terminal acetate group. Hence, here due addition to Equilibrium (5) \& (6) should be considered, which takes place above a $\mathrm{pH} \approx 2$ (see Figure 2 ).

$$
\begin{gathered}
\mathrm{H}_{3}(\mathrm{~L})^{+} \rightleftharpoons \mathrm{H}^{+}+\mathrm{H}_{2}(\mathrm{~L}) \\
K_{\text {Asp }}^{H}=\left[\mathrm{H}_{2}(\mathrm{~L})\right]\left[\mathrm{H}^{+}\right] /\left[\mathrm{H}_{3}(\mathrm{~L})^{+}\right]
\end{gathered}
$$

Here, the aforementioned reaction is not considered further.

\subsection{Stability of Binary and Ternary Complexes}

If we abbreviate for simplicity associating with $\mathrm{Ca}^{2+}$, $\mathrm{Mg}^{2+}, \mathrm{Mn}^{2+}, \mathrm{Co}^{2+}, \mathrm{Cu}^{2+}$, and $\mathrm{Zn}^{2+}$ with $\mathrm{M}^{2+}$, then one may write the following two Equilibrium of (7)(8)(9) (10):

$$
\begin{gathered}
\mathrm{M}^{2+}+\mathrm{H}(\mathrm{L})^{-} \rightleftharpoons \mathrm{M}(\mathrm{H} ; \mathrm{L})^{+} \\
K_{M(H ; A s p)}^{M}=\left[\mathrm{M}(\mathrm{H} ; \mathrm{L})^{+}\right]\left[\mathrm{M}^{2+}\right] /\left[\mathrm{H}(\mathrm{L})^{-}\right]
\end{gathered}
$$


Table 1. Comparison of the stability constants of binary complexes of Asp and TTA with $\mathrm{M}^{2+}$ at $25^{\circ} \mathrm{C}, \mathrm{I}=0.1 \mathrm{M}, \mathrm{NaNO}_{3}{ }^{*}$.

\begin{tabular}{ccccc}
\hline No. & Species & $\log \mathbf{K}_{\text {(Asp) }}$ & $\log \mathbf{K}_{\text {(TTA) }}$ & $\Delta \log \mathbf{K}$ \\
\hline 1 & $\mathrm{H}_{2}(\mathrm{~L})$ & $3.72 \pm 0.03$ & $3.09 \pm 0.07$ & - \\
2 & $\mathrm{H}(\mathrm{L})$ & $9.90 \pm 0.03$ & $4.19 \pm 0.05$ & - \\
3 & $\mathrm{Mg}^{2+}$ & $2.50 \pm 0.06$ & $1.90 \pm 0.05$ & $0.60 \pm 0.05$ \\
4 & $\mathrm{Ca}^{2+}$ & $1.26 \pm 0.06$ & $1.80 \pm 0.05^{1}$ & $-0.54 \pm 0.08$ \\
5 & $\mathrm{Mn}^{2+}$ & $3.91 \pm 0.03$ & $4.08 \pm 0.08$ & $-0.17 \pm 0.09$ \\
6 & $\mathrm{Co}^{2+}$ & $6.69 \pm 0.06$ & $3.27 \pm 0.08$ & $3.42 \pm 0.10$ \\
7 & $\mathrm{Cu}^{2+}$ & $8.78 \pm 0.02$ & $3.65 \pm 0.07$ & $5.13 \pm 0.07$ \\
8 & $\mathrm{Zn}^{2+}$ & $5.35 \pm 0.06$ & $2.69 \pm 0.07$ & $2.66 \pm 0.09$ \\
\hline
\end{tabular}

*The given errors are three times the standard error of the meanvalue or the sum of the propabable systematic errors. ${ }^{1}[6,23]$

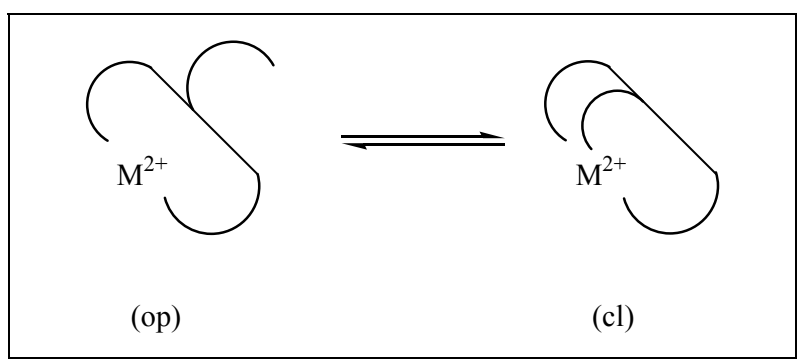

Figure 2. Schematic equilibrium between an "open" isomer $\mathrm{M}(\mathrm{Asp})_{\mathrm{op}}$ and a "closed" species, M(Asp) $)_{\mathrm{cl}}$, see Eq.11 \& 12.

$$
\begin{gathered}
\mathrm{M}^{2+}+(\mathrm{L})^{2-} \rightleftharpoons \mathrm{M}(\mathrm{L}) \\
K_{M(\text { Asp })}^{M}=[\mathrm{M}(\mathrm{L})]\left[\mathrm{M}^{2+}\right] /\left[\mathrm{L}^{2-}\right]
\end{gathered}
$$

The experimental data of the potentiometric $\mathrm{pH}$ titrations may be completed by considering the above-mentioned Equilibrium (1) \& (2) through (9) \& (10), if the evaluation thereof is not carried into the $\mathrm{pH}$ range, where hyrdoxo complex formation occurs.

The schematic illustration of equilibrium between different protonated species is shown in Figure 2. Based on this point we can define following equilibrium:

$$
\begin{aligned}
& \mathrm{M}^{2+}+(\mathrm{L})^{2-} \rightleftharpoons \mathrm{M}(\mathrm{L}) \rightleftharpoons \mathrm{M}(\mathrm{L})_{\mathrm{op}} \rightleftharpoons \mathrm{M}(\mathrm{L})_{\mathrm{cl}} \\
& K_{M(\text { Asp })}^{M}=\left(\left[\mathrm{M}(\mathrm{L})_{\mathrm{op}}\right]\left[\mathrm{M}(\mathrm{L})_{\mathrm{cl}}\right]\right) /\left[\mathrm{M}^{2+}\right]\left[\mathrm{L}^{2-}\right]
\end{aligned}
$$

TTA can represent the open form.

\subsection{Potentiometric Analyses}

Now we are able to compare the stability constants of two species M(TTA) and M(Asp). It could easly distinguish that thos constants of $\mathrm{M}(\mathrm{Asp})$ is generally larger than those of the corresponding M(TTA) species. This increased stability of the difference between the stability constants as defined in Eqs.11 \& 12 [15-18]:

$$
\Delta \log \mathrm{K}=\log \mathrm{K}_{(\mathrm{Asp})}-\log \mathrm{K}_{(\mathrm{TTA})}
$$

Positive amount of $\Delta \log \mathrm{K}$ indicates the back-binding of the metal ion, with other words the bilding of chelate (see Figure 2).

According Figure 2 we can define the dimensionless equilibrium constant $\mathrm{K}_{\mathrm{I}}$ as follows:

$$
\mathrm{K}_{\mathrm{I}}=\left[\mathrm{M}(\mathrm{Asp})_{\mathrm{cl}}\right] /\left[\mathrm{M}(\mathrm{Asp})_{\mathrm{op}}\right]
$$

The equilibrium constant may be deduced [19-22] from the experimentally accessible overall stability constant, $K_{M(\text { Asp })}^{M}$ using Eq.15,

$$
\mathrm{K}_{\mathrm{I}}=\left(K_{M(A s p)}^{M} / K_{M(A s p)}^{M}\right)-1
$$

Now we can combine Eqs.7 and 9 to receive Eq.16,

$$
\mathrm{K}_{\mathrm{I}}=10^{\Delta \log \mathrm{K}}-1
$$

The procentuage anount of closed species in Eq.17, which represent the intramilecular interactions i.e. chelate bilding can be calculated via Eq.17 as follows,

$$
\% \mathrm{M}(\operatorname{Asp})_{\mathrm{cl}}=100\left(\mathrm{~K}_{\mathrm{I}} / 1+\mathrm{K}_{\mathrm{I}}\right)
$$

This result is summarized in Table 1. As we can see from these results, the stability constants of the binary complexes, such as M(L) (Figure 3) were refined separately using the titration data of this system in a $1: 1$, ligand: $\mathrm{M}^{2+}$ ratio in the same conditions of temperature and ionic strength (according Eqs.9 \& 10), as they were in good agreement with reported value $[6,23]$. We didn't receive reasonable results for $K_{M(H ; A s p)}^{M}$. The stability constants of Table 1 show the following trends. The obtained order for TTA is $\mathrm{Mn}^{2+}>\mathrm{Co}^{2+}<\mathrm{Cu}^{2+}>\mathrm{Zn}^{2+}$. The corresponding order for Asp is $\mathrm{Mn}^{2+}<\mathrm{Co}^{2+}<\mathrm{Cu}^{2+}$ $>\mathrm{Zn}^{2+}$. The last observed stability order for aspartate follows the Irving-Williams sequence [24].

As we can use from Figure 3, aspartic chelates metal ions weakly via the amino nitrogen and carbonyl oxygen. A stronger chelation occurs upon an amide nitrogen bound hydrogen by some metal ions such as $\mathrm{Cu}^{2+}$. This reaction occurs in neutral $\mathrm{pH}$ conditions $(\mathrm{pH} \approx 7)$ with $\mathrm{Cu}^{2+}$. A crystal structure of $\mathrm{M}^{2+}$ chelate with a structure analogous has been studied [25].

If we now consider the two isomers which occure in equillibrium Figure 2 as $\mathrm{M}(\mathrm{Asp})_{\mathrm{op}}$ and $\mathrm{M}(\mathrm{Asp})_{\mathrm{cl}}$, we can define the chelate equilibrium constants $\mathrm{K}_{\mathrm{I}}$ by Eq.15. 
In the last column of Table 1 are summarized the results of the difference between stability constants of TTA and Asp Eq.13. The amount of $\Delta \log \mathrm{K}$ for $\mathrm{Mn}^{2+}$ is not significant, but in the case of other metal ions such as $\mathrm{Co}^{2+}, \mathrm{Cu}^{2+}$ and $\mathrm{Zn}^{2+}$ the differences are remarkable. The increased amount of stability constants in the case of Asp shows that the formation of chelate is taken place. This means the additional complex stability is a degree of the affinity of the metal ions for Asp. One can now translate this affinity in percent chelate formation degree. Hence, if both these chelate isomers do exist, the percentages calculated for $\mathrm{M}(\mathrm{Asp})_{\mathrm{cl}} \mathbf{E q . 1 7}$ and listed in the last column of Table 1 comprise the sum of percentages for both isomers.

However, as we have seen above, for the persent cases $\Delta \operatorname{logK}$ holds and hence values for the chelate bilding, which then also allow calculation of percentage of the closed isomer M(Asp) $)_{\mathrm{cl}}$ with Eq.17. The chelate- bilding can occure in inner-sphere or outer-sphere form via amid group. The results show that the total percentage of chelate - bilding according Eq.17 for $\mathrm{Mg}^{2+}$ is about $75 \%$ and for the other metal ions such as $\mathrm{Co}^{2+}, \mathrm{Cu}^{2+}$, and $\mathrm{Zn}^{2+}$ is $\approx 100 \%$. In other words, in Figure 2, the equilibrium is for the last three metal ions completely on the right site. Because of high increased stability we can draw conclusion, that the releasing of some chelated metal ions such as $\mathrm{Co}^{2+}, \mathrm{Cu}^{2+}$, and $\mathrm{Zn}^{2+}$ in biological systems is relatively strong. But also in comparison with "hard" metal ions like $\mathrm{Mg}^{2+}, \mathrm{Ca}^{2+}$, and $\mathrm{Mn}^{2+}$ is the releasing much easier. The properties can play a significant role for catalytic activity of such metal ions in biological systems.

These thermodynamic constants help us now to understand why poly-L-aspartic acid and poly-L-histidine is presented as binding agents to enhance microdialysis recovery of metal ions. Enhancing microdialysis recovery of metal ions by incorporating poly-L-aspartic acid and poly-L-histidine in the perfusion liquid is a very successful method [13]. The data from these studies demonstrate the suitability of poly-L-aspartic as selective and effective binding agents that enhance the microdialysis recovery of metal ions. Application of the optimised conditions to the determination of $\mathrm{Pb}$ and $\mathrm{Cu}$ in a wastewater sample confirmed the versatility of microdialysis, as higher recoveries of $\mathrm{Cu}$ were obtained with poly-L-aspartic acid compared to direct determination.

Although monitoring of metal ions at trace levels is of interest, few studies that involve in situ sampling and sample clean up of metal ions have been reported. Determination of metal ions in environmental samples is necessary in order to give a reflection of the level of pollution in the ecosystem [26]. Similarly, in biological systems, the knowledge of concentration of metal ions is essential for the understanding of both physiological and pathological conditions [27-29].

Biological systems have the ability to selectively bind to metals taking advantage of the array of protein binding functionalities [30]. Short chain synthetic biopolymers also have unique, strong and selective binding properties offered by their constituent amino acids.

Poly-L-aspartic acid and poly-L-histidine have also shown selectivity for trace metal extraction when immobilised on chromatographic substrates [31,32]. Amino acids and peptides have been shown to bind to transition metal ions with a high degree of selectivity [33]. The binding sites are associated with nitrogen, sulphur and oxygen donors from histidine, tyrosine, glutamic or aspartic acids and cysteine $[33,34]$. The 'harder' carboxylate groups of poly-Laspartic acid prefer to bind with $\mathrm{Cu}$, which is a 'harder acid' metal [32]. The poliovirus RNA-dependent RNA polymerase, 3Dpol, is known to share a region of sequence homology with all RNA polymerases centered at the GDD amino acid motif. The two aspartic acids have been postulated to be involved in the catalytic activity and metal ion coordination of the enzyme [35].

Interactions between aspartic acid (Asp) and cytidine5 -monophosphate (CMP) in metal-free systems as well as the coordination of $\mathrm{Cu}$ (II) ions with the above ligands were studied. The composition and overall stability constants of the species formed in those systems were determined [36]. Amino acid chelated minerals, also referred to as chelated minerals or mineral chelates, are minerals that have been chemically engineered to become more bioavailable to our body. Amino acids act as carriers to ship the much-needed minerals to the destination (the small intestine) where consumption takes place.

Elixir Industry has tested many self-claimed "mineral chelates" available on the market and found most of them are merely mixtures of amino acids and inorganic minerals [37]. Why are amino acid chelated minerals superior to common inorganic minerals?

In contrast to the high-tech nature of chelated minerals, common inorganic minerals that are used in majority of vitamin and mineral supplements today are minerals that are easily found in nature or in the earth, in the forms of rock or limestone. First of all, chelated minerals are substantially more bioavailable than common inorganic minerals. For mineral to be absorbed by our body, it has to be soluble in the luminal fluid of the small intestine. The $\mathrm{pH}$ of the small intestinal fluid below the duodenum is 7.0-7.2. Most inorganic minerals will form insoluble hydroxides and become nonabsorbable at this $\mathrm{pH}$. Chelated minerals, on the other hand, are well shielded by amino acids, and will not precipitate to cause absorption problems. Which we can see in the results of the Table 1 last column and Figure 3. 


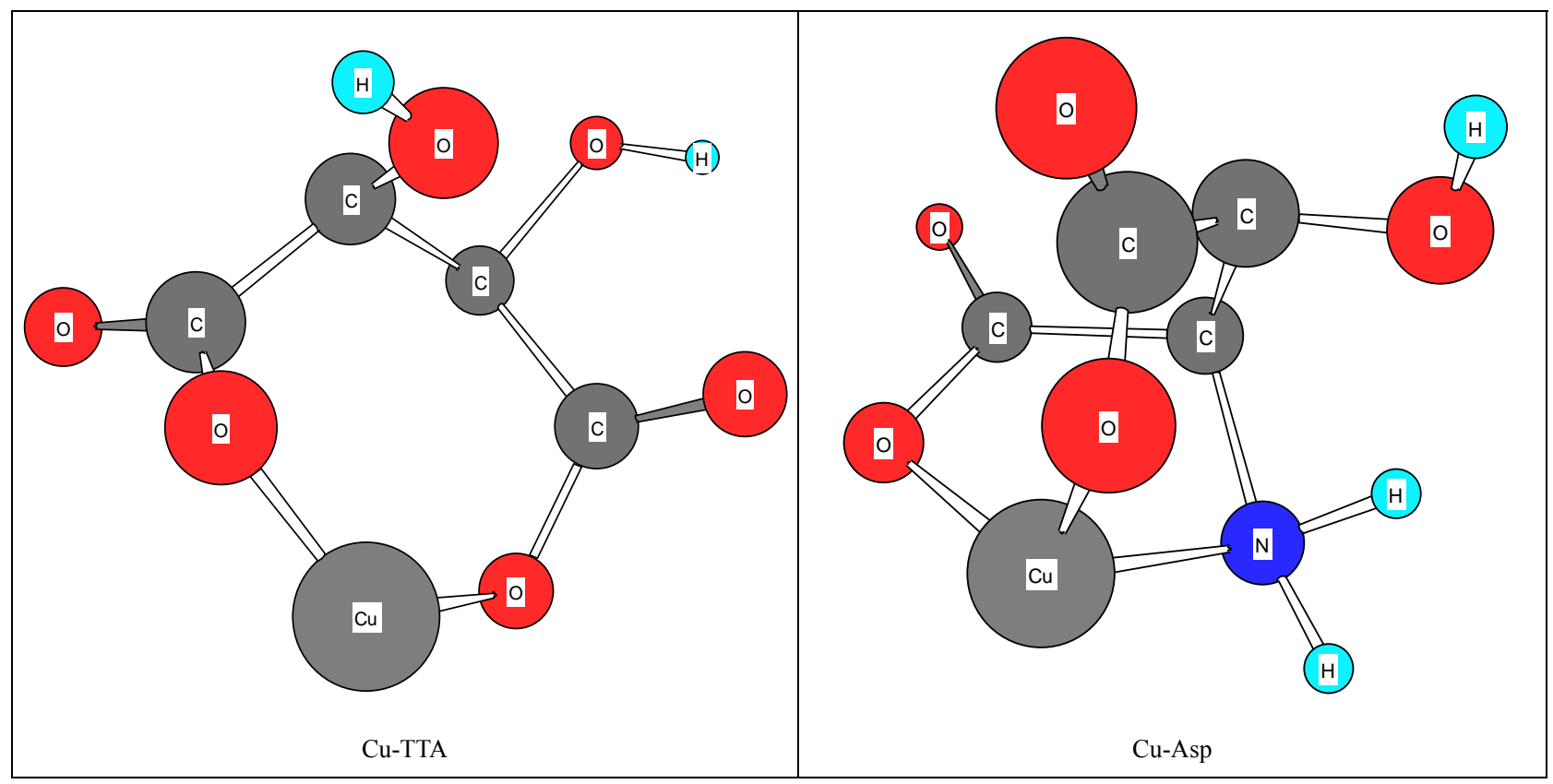

Figure 3. Schematic structures of the species with interactions according to equilibrium (5) for $\mathrm{Cu}(\mathrm{Asp})$. The structure in the right part of the figure was drawn with the programCS Chem 3D, version 3.5, from Cambridge Software Corporation.

Secondly, using chelated minerals also prevents gastrointestinal (G.I.) distress. As mentioned above inorganic minerals can cause magma precipitation. This precipitation can coat the mucous membrane, resulting in diarrhea and constipation. Chelated minerals, however, do not form magma precipitation, and using them will not cause stomach disorders. In addition chelated minerals are kept intact from many compounds regularly found in foodstuffs. Those compounds that commonly exist in foods, such as carbonates, phosphates, oxalates and phytates, oftentimes attach themselves to inorganic minerals to form insoluble precipitates. These precipitates will further reduce the absorption of minerals in the small intestine.

Finally chelated minerals help protect vitamin stability. Inorganic metal ions may serve as a catalyst to further the oxidation and degradation of vitamins. Chelated minerals, on the other hand, are well shielded by bonded organic ligands. Which we can consider in Figure 3. They will not come in contact with vitamin molecules; thus, the vitamins will be protected from oxidation and degradation. And since magma precipitation is prevented, chelated minerals will not absorb vitamins and cause them to become nonabsorbable - problems that common inorganic mineral are known to cause. As we can see, in Figure 3, TTA is not able to bild three dendate chelate like Asp, so that metal ions are not enough shielded. As consequence metal ions can take part in substituation reactions.

There are different types of amino acids. L-Aspartic
Acid plays a vital role in energy production and is a major excitatory neurotransmitter. It is involved in building DNA (genetic structures in cells), in carbohydrate metabolism \& protein metabolism. It helps detoxify ammonia in the body, helps reduce fatigue and depression, and it also supports liver protection. Mineral Chelates (for example AbSolu) are chelates of L-Aspartic Acid and one of the minerals such as calcium, magnesium and zinc. They are chemically synthesized by proprietary technology developed by Elixir Industry [37]. New products are anhydrous chelates of two L-Aspartic Acid molecules and a single metal ion. The technology of achieving this structure is patented and was jointly developed by Elixir Industry and the Chinese National Institute of Pharmaceutical Industry. Mineral Chelates to be completely soluble over a wide range of $\mathrm{pH}$ values. The chelated minerals are soluble in the small intestine for absorption and subsequent bio-utilization. These products are compatible with most nutritional additives commonly used in formulations and tableting applications.

There are different types of amino acids. Nutrition scientists selected L-Aspartic acid based on many additional benefits that come with it. Most of the competetors' products contain two or more crystalline water in their molecules. Theoretically those products should not be referred to as "chelates" and the bonding (if indeed exists) of amino acid molecules to mineral ions is vulnerable. These products are anhydrous chelates of two L-Aspartic Acid molecules and a single metal ion. 


\section{REFERENCES}

[1] IUPAC-IUBMB Joint Commission on Biochemical Nomenclature. Nomenclature and Symbolism for Amino Acids and Peptides, Recommendations on Organic \& Biochemical Nomenclature, Symbols \& Terminology etc. Retrieved on 2007-05-17.

[2] Nelson, D.L. and Cox, M.M. (2000) Lehninger, principles of biochemistry. 3rd Edition, Worth Publishing, New York.

[3] Stryer, L. (1995) Biochemistry. 4th Edition, W. H. Freeman and Company, New York.

[4] Chen, P.E., Geballe, M.T., Stansfeld, P.J., Johnston, A.R., Yuan, H.J., Jacob, A.L., Snyder, J.P., Traynelis, S.F. and Wyllie, D.J.A. (2005) Structural features of the glutamate binding site in recombinant NR1/NR2A N-Methyl-Dlartate receptors determined by site-directed mutagenesis and molecular modeling. Molecular Pharmacology, 67, 1470-1484.

[5] Dunn, M.S. and Smart, B.W. (1963) DL-Lartic acid. Organic Syntheses, 4, 55.

[6] Martel, A.E. (2006) Critical stability constants of metal complexes, 26.

[7] Ritchie, S.M.C., Bachas, L.G., Olin, T., Sikdar, S.K. and Bhattacharyya, D. (1999) Surface modification of silicaand cellulose-based microfiltration membranes with functional polyamino acids for heavy metal sorption. Langmuir, 15(19), 6346-6357.

[8] Xiao, S., Textor, M., Spencer, N.D. and Sigrist, H. (1998) Covalent attachment of cell-adhesive, (arg-gly-asp) containing peptides to titanium surfaces. Langmuir, 14, 5507.

[9] Konishi, Y., Shimaoka, (1998) Sorption of rare-earth ions on biopolymer gel beads of alginic acid. J. and Asai, $S$ Reactive and Functional Polymers, 36, 197.

[10] Reichert, J. and Binner, J.G.P. (1996) Processing of hydroxyapatite ceramic foams. Journal of Materials Science, 31, 1231.

[11] Bonn, G., Reiffenstuhl, S. and Jandik, P. (1990) Ion chromatography of transition metals of alginic acid. Journal Chromatogr, 499, 669.

[12] Bhattacharyya, D., Hestekin, J.A., Brushaber, P., Cullen, L., Bachas, L.G. and Sikdar, S.K. (1998) Novel poly-glutamic acid functionalized microfiltration membranes for sorption of heavy metals at high capacity. Journal of Membrane Science, 141, 121.

[13] Dikabo, M. and Nelson, T. (2003) Maximising metal ions flux across a microdialysis membrane by incorporating poly-1-aspartic acid, poly-l-histidine, 8-hydroxyquinoline and ethylenediaminetetraacetic acid in the perfusion liquid. Analytica Chimica Acta, 482(1), 91-97.

[14] Sajadi, S.A.A., Alamolhoda, A.A. and Alavi, A.N. (2009) Investigation of interactions of methionine complexes with metal ions. Scientica Iranica.

[15] Sajadi, S.A.A., Song, B. and Sigel, H. (1998) Ternary Complexes in Solution. Intramolecular stacking interactions in mixed ligand complexes formed by copper (ii), 2,2-bipyridyl or 1,10-phenantroline and a pyrimidinenucleoside 5-diphosphate $\left(\mathrm{CDP}^{3-}, \mathrm{UDP}^{3-}, \mathrm{dTDP}^{3-}\right)$. Inorganica Chimica Acta, 283, 193-201.

[16] Sajadi, S.A.A., Song, B. Gregan, F. and Sigel, H. (1999)
Acid-base and metal ion-coordinating properties of pyrimidine-nucleoside 5-diphosphate (cdp, udp, dtdp) and of several simple diphosphate monoesters. Establishment of relations between complex stability and diphosphate. Inorganica Chimica, 38(3), 439-448.

[17] Sajadi, S.A.A., Song, B. Gregan, F. and Sigel, H. (1997) Ternary complexes in solution. intramolecular stacking interactions in mixed ligand complexes formed by copper (ii), 2,2-bipyridyl or 1,10-phenantroline and n-butyl diphosphate $\left(\mathrm{BuDP}^{3-}\right)$ or phenyl diphosphate $\left(\mathrm{phdp}^{3-}\right)$. Bulletin of Chemical Society of Ethiopia, 11(2), 121-130.

[18] Sajadi, S.A.A., Bastian, M and Sigel, H. (1995) Stabilities of metal ion complexes of adenosine 5-diphosphate $\left(\mathrm{ADP}^{3-}\right)$ and uridine 5-diphosphate $\left(\mathrm{UDP}^{3-}\right)$. Journal of Inorganic Biochemistry, 59(2-3), 139.

[19] Handbook of Chemical and Physics, 55, (1975) D-129.

[20] Miranda, J.L. and Felcman, J. (2003) Study on guanidino-carboxylate interactions in copper (II) ternary complexes of guanidinoacetic acid with glutamic and aspartic acids. Polyhedron, 22, 225-233.

[21] Felcman, J. and Miranda, J.L. (1997) A potentiometric study of guanidinoacetic acid complexation with the ions $\mathrm{Mn}(\mathrm{II}), \mathrm{Co}(\mathrm{II}), \mathrm{Ni}(\mathrm{II}), \mathrm{Cu}(\mathrm{II}), \mathrm{Zn}(\mathrm{II}), \mathrm{Cd}(\mathrm{II})$ and $\mathrm{Pb}(\mathrm{II})$. Journal of the Brazilian Chemical Society, 8, 575.

[22] Voet, D. (1997) Biochemistry, John Wiley, New York, 560.

[23] Pettit, L.D. and Powel, H.K.J (1998) IUPAC stability conatants database, release 3. 3.02 Edition, Academic Software Timble, UK.

[24] Irving, H. and Williams, R.J.P. (1953) The stability of transition-metal complexes. Jorunal of Chemical Society, 3192-3210.

[25] Tsukihara, T. and Katsube, Y. (1972) The crystal and molecular structure of averufin. Bulletin of the Chemical Society of Japan, 45, 1367.

[26] Torto, N., Mwatseteza, J. and Sawula, G. (2001) Determination of saccharides in wastewater from the beverage industry by microdialysis sampling, microbore high performance anion exchange chromatography and integrated pulsed electrochemical detection. Analytica Chimica Acta, 456, 253.

[27] Janle, E.M., Cregor, M. and Sojka, J. (2001) Determination of glucose in microliter samples of in vivo ultrafiltrates and microdialysates using amperometric flow injection analysis with an enzymatic reactor. Current Separations, 19, 80.

[28] Allen, D.D. and Yokel, R.A. (1992) Dissimilar aluminum and gallium permeation of the blood-brain barrier demonstrated by in vivo microdialysis. Journal of Neurochemistry, $\mathbf{5 8 ,} 903$.

[29] www.niddk.nih.gov

[30] Guo, M., Zou, H., Wang, H., Kong, L. and Ni, J. (2001) Binding of metal ions with protein studied by a combined technique of microdialysis with liquid chromatography. Analytica Chimica Acta, 443, 91.

[31] Kiseleva, G., Kebets, P.A. and Nesterenko, P.N. (2002) Enhancing microdialysis recovery of metal ions by incorporating poly-L-aspartic acid and poly-L-histidine in the perfusion liquid. Analyst, 126, 2119.

[32] Ritchie, S.M.C., Bachas, L.G., Olin, T., Sikdar, S.K. and Bhattacharyya, D. (1999) Development and characterization of a microfiltration membrane catalyst containing 
sulfonated polystyrene grafts. Langmuir, 15, 6346.

[33] Gooding, J.J., Hibbert, D.B. and Yang, W. (2001) Electrochemical metal ion sensors. Exploiting amino acids and peptides as recognition elements. Sensors, 1, 75.

[34] Battistoni, A., Pacello, F., Mazzetti, A.P., Capo, C., Kroll, J.S., Langford, P.R., Sansone, A., Donnarumma, G., Valenti, P. and Rotilio, G. (2001) A histidine-rich metal binding domain at the $\mathrm{N}$ terminus of $\mathrm{Cu}, \mathrm{Zn}$-superoxide dismutases from pathogenic bacteria a novel strategy for metal chaperoning. The Journal of Biological Chemistry, 276, 30315.

[35] Jablonski, S.A. and Morrow, C.D. (1995) Mutation of the aspartic acid residues of the GDD sequence motif of po- liovirus RNA-dependent RNA polymerase results in enzymes with altered metal ion requirements for activity. Journal of Virology, 69(3), 1532-1539.

[36] Romualda, B.J., Gasowska, A. and Lomozik, L. (2008) Complexes of $\mathrm{Cu}(\mathrm{II})$ iions and noncovalent interactionns in systems with L-aspartic acid and cytidine-5'-monophosphate. Bioinorganic Chemistry and Applications, 2008.

[37] The technology of achieving this structure is patented and was jointly developed by Elixir Industry, Las Vegas, NV 89104-7900, USA, and the Chinese National Institute of Pharmaceutical Industry. 